\title{
VALIDACIJA UPITNIKA STAVA O BEZBEDNOSTI HRANE TOKOM PUTOVANJA - PRIMENA MREŽNIH PLATFORMI U ISTRAŽIVANJIMA
}

\author{
Nataša Kilibarda, \\ Dušan Borovčanin*, \\ Ivana Brdar, \\ Miloš Milošević \\ Univerzitet Singidunum, \\ Beograd, Srbija
}

Odgovorno lice:

Dušan Borovčanin

e-pošta:

dborovcanin@singidunum.ac.rs

\section{Rezime:}

Cilj ovog rada bila je konstrukcija i validacija Upitnika stava o bezbednosti hrane tokom putovanja (SBH-P). Na uzorku od 746 ispitanika urađene su desktriptivna, korelaciona i analiza pouzdanosti i analiza varijanse. Rezultati analiza govore u prilog dobrih metrijskih karakteristika mernog instrumenta što predstavlja uslov za njegovo dalje primenjivanje $\mathrm{u}$ istraživanjima bezbednosti hrane tokom putovanja. Podaci su prikupljani preko Amazonove mrežne platforme MTurk, koja se pokazala kao efikasan način formiranja velikog globalnog uzorka.

Ključne reči:

MTurk, bezbednost hrane, putovanje, validacija, upitnik .

\section{UVOD}

U cilju očuvanja i unapređenja javnog zdravlja, između ostalih činioca, veoma je važno da se obezbede dovoljne količine higijenski ispravne odnosno bezbedne hrane ljudima. Bezbedna hrana je hrana koja nije štetna po zdravlje ljudi, ukoliko se priprema i/ili konzumira u skladu sa namenjenom upotrebom (Codex Alimentarius). Konzumiranje hrane koja nije bezbedna dovodi do pojave oboljenja koja se jednim imenom nazivaju bolesti prenosive hranom (Foodborn disease). Zvanični podaci Svetske zdravstvene organizacije navode podatak da je riziku od bolesti prenosivih hranom u čitavom svetu izloženo milijarde ljudi, milion njih oboli godišnje, dok pojedini slučajevi imaju čak i smrtni ishod. Procenjuje se i da 600 miliona ljudi ( 1 u 10 ljudi na svetu) godišnje oboli konzumirajući hranu koja nije bezbedna, a da 420.000 ljudi svake godine umre od posledica konzumiranja nebezbedne hrane [1]. Pored opisanog uticaja na pojedinca, nebezbedna hrana, dovodi do značajnih ekonomskih gubitaka pojedinih država koji nastaju kao posledica smanjenog izvoza hrane, šteta koje se nanose poljoprivredi ili se pak smanjuju prihodi od turizma, budući da rejting turističkih destinacija značajno opada usled pojave nebezbedne hrane [2].

Sa aspekta turizma, pojava bolesti prenosivih hranom na putovanjima, karakteriše se pojavom stomačnih tegoba poznatijih kao putničke dijareje. Ovaj problem pogađa od $20 \%$ do $60 \%$ putnika, i to uglavnom 
one koji tokom svojih putovanja posećuju nerazvijene zemlje [3]. U najvećem broju slučajeva simptomi bolesti su takvi da ne dovode do ozbiljnijih posledica po zdravlje, ali svakako u velikoj meri umanjuju uživanje u samom putovanju. U oko $20 \%$ do $40 \%$ slučajeva putnik mora da miruje u trajanju od 1 do 2 dana, $3 \%$ obolelih zatraži medicinsku pomoć, dok $1 \%$ posto mora da se hospitalizuje zbog pojave dehidratacije i težih oblika oboljenja [4].

Današnje vreme karakteriše se zahtevima koji se odnose na brže obavljanje posla, brže donošenje odluka sa manje korišćenih resursa, a da pri tome rezultati obavljenog procesa budu efikasniji i sa manje grešaka. Upotreba informacionih tehnologija u oblasti bezbednosti hrane, može pružiti odgovore na ovako visoko postavljene zahteve i to na način da ljudsko zdravlje ne bude ugroženo, odnosno da pruži značajnije garancije da je hrana koja se konzumira bezbedna. Samo neki od primera upotreba IT u oblasti bezbednosti hrane su:

- Sektori nabavke hrane koji su zasnovani na informacionim tehnologijama, omogućavaju svim učesnicima u lancu hrane, proizvođačima, dobavljačima i potrošačima, sledljivost duž celog lanca hrane, od „farme do trpeze“. Na ovaj način, omogućena je komunikacija svih učesnika u lancu hrane u realnom vremenu, što doprinosi blagovremenom prenošenju informacija o eventualnim rizicima, samim tim i pravovremeno preduzimanje preventivnih ili korektivnih mera, čime se čuva zdravlje ljudi.

- Specifični softveri koji su dostupni za pakovanja mesa i proizvode od mesa pružaju mogućnost da se održava i reguliše temperatura transporta ovih lako kvarljivih proizvoda, što doprinosi očuvanju njihove bezbednosti.

- Podaci koji se čuvaju i sakupljaju u cilju implementacije, sprovođenja i verifikacije HACCP sistema u objektima koji posluju hranom, primenom tehnologija zasnivanim na cloud sistemu, omogućavaju da se podaci ažuriraju i sinhronizuju i da im se može pristupiti iz različitih delova sveta što u velikom stepenu obezbeđuje i osigurava funkcionisanje HACCP i njegovo sprovođenje u cilju preventivnog delovanja i proizvodnje bezbedne hrane [5].

- Upotreba IT u istraživanjima koje koriste mrežne platforme u cilju prikupljanja podataka, koji se koriste za analizu i procenu stavova i znanja potrošača vezane za bezbednost hrane
Definicija bezbednosti hrane, ukazuje na značajan uticaj ljudskog faktora na samu bezbednost hrane, $s$ obzirom da ljudi svojim neadekvatnim i nepravilnim postupcima sa hranom prilikom čuvanja, pripreme i konzumiranja, mogu uticati nepovoljno na njenu bezbednost. Iz tog razloga, važno je sprovoditi kontinuiranu edukaciju potrošača, ali i istraživanja u cilju prikupljanja i analize podataka o stavovima potrošača i njihovog znanja o postupcima koji se odnose na rukovanje hranom [6].

Zbog obima teme bezbednosti hrane, $\mathrm{u}$ ovom radu predmet analize biće sužen na specifičan domen bezbednosti hrane na putovanjima. Polazeći od opšte prihvaćene definicije stavova kao relativno trajnih dispozicija koje se sastoje od međusobno neraskidivo povezanih kognitivnih, konativnih i emocionalnih komponenti i koje se manifestuju kroz specifično ponašanje (bihejvioralna komponenta), odnosno kao sklonost da se razmišlja, oseća, reaguje i ponaša na određeni način [7], stav o bezbednosti hrane tokom putovanja definisan je kao skup međusobno povezanih informacija, znanja, navika, potreba, motiva i emocija koji rezultuju više ili manje bezbednim ponašanjem u domenu ishrane na putovanjima.

Tema bezbednosti hrane na putovanjima iako veoma važna kako sa aspekta javnog zdravlja, tako i sa turističkog, odnosno ekonomskog aspekta nije na zadovoljavajuć način obrađena u dosadašnjim istraživanjima [8]. Osnovni preduslov za otklanjanje ovog nedostatka, odnosno povećanja obima istraživanja bezbednosti hrane na putovanjima je konstrukcija validnih mernih instrumenata što takođe nije bio slučaj u dosadašnjoj istraživačkoj praksi. Zbog toga je cilj ovog rada konstrukcija i validacija mernog instrumenta koji će obezbediti uslove za dalje istraživanje teme bezbednosti hrane tokom putovanja.

\section{PRIMENA MREŽNIH PLATFORMI U CILJU EFIKASNOG PRIKUPLJANJA PODATAKA}

Ranije teorijske studije ukazale su na veliki potencijal upotrebe mrežnih platformi u formiranju velikih globalnih uzoraka ispitanika za potrebe naučnih istraživanja [9], što je jedan od osnovnih preduslova ispravne validacije mernih instrumenata. Pored, sada već tradicionalnih metoda prikupljanja podataka uz pomoć kompjutera putem email-a, društvenih mreža i mrežnih (on-line) upitnika, pojava platformi koje omogućavaju susret ponude i tražnje na tržištu jednostavnih poslova (crowdsourcing) predstavlja jedan od pionirskih vidova ostvarenja opisanog potencijala. Kraudsorsing je termin 
koji među prvima iskoristio Džef Hou (Jeff Howe) definišući ga kao ponudau posla za anonimne spoljne saradnike (outsourcing) putem javnog poziva [10]. Jedna od najpopularnijih platformi ove vrste je i Amazonov Mehanikal Turk (Amazon Mechanical Turk) koji je nastao 2005. godine i služi za angažovanje spoljnih saradnika za pojedince i privredne subjekte na virtuelnim poslovima [11]. Ubrzo nakon njegovog nastanka, istraživači na akademskim institucijama i institutima su primetili da bi ovo mogao biti odličan resurs za prikupljanje podataka, ali se postavilo veliko pitanje pouzdanosti prikupljanja podataka na ovaj način. Do danas, sprovedeno je nekoliko studija koje su analizirale i predstavile strukturu ispitanika u istraživanjima sprovedenim preko MTurk-a [12, 13, 14]. Svi su saglasni u tome da ne postoje značajne rezlike u demografskoj strukturi učesnika $\mathrm{u}$ istraživanjima sprovedenih putem MTurk-a i drugih tradicionalnih metoda prikupljanja podataka. Štaviše, u pojedinim vrstama istraživanja ispitanici sakuljeni putem MTurk-a pokazuju se kao pouzdaniji izvor u odnosu na druge metode [12]. Pored klasičnih istraživanja putem popunjavanja upitnika, MTurk se pokazao i kao pouzdan alat za vršenje oeksperimentalnih istraživanja [15]. Upotreba Amazonovog MTurk-a dodatno je omasovljena standardiazcijiom procedura korišćenja ovog alata u društvenim istraživanjima [16]. Razlog za ovako široku upotrebu MTurka, leži sigurno i u činjenici da je danas internet prisutan na preko 26 milijardi uređaja ili na više od 3 puta više uređaja nego što postoji ljudi na zemaljskoj kugli [17]. Zbog svega navedenog MTurk je odabran kao platforma za prikupljanje podataka i u ovom istraživanju što će poslužiti i kao još jedna u nizu ilustracija prednosti upotrebe IT tehnologiju u naučnoistraživačkom radu, ovoga puta vezanom za specifičan domen bezbednosti hrane.

\section{METOD}

Istraživanje je izvedeno u dve faze. Prva faza se odnosila na konstrukciju upitnika, dok su u drugoj prikupljani podaci u cilju njegove validacije.

\section{Konstrukcija upitnika}

Nakon usmenog intervjua sa 20 ispitanika, formirana je prva verzija upitnika od 45 pitanja koja su se ticala kognitivnih, konativnih, emotivnih i bihejvioralnih komponenti stava o bezbednosti hrane tokom putovanja. Prvom verzijom upitnika izvedeno je usmeno anketiranje uzorka od 30 profesora i asistenata svih usmerenja Univerziteta Singidunum i Beogradskog Univerziteta na osnovu koga je formirana finalna verzija upitnika od 32 tvrdnje, uputstvo za ispitanike i finalna formulacija tvrdnji. Prilikom konstrukcije finalne verzije upitnika vodilo se računa da emotivna, kognitivna, konativna i bihejvioralna komponenta merenog stava budu ravnopravno zastupljene, ali i o ekonomičnosti i izbegavanju redundantosti tokom istraživanja. Na kraju je upitnik za potrebe validacione studije preveden na engleski jezik tehnikom dvostrukog prevođenja u nazad (back translation).

\section{Prikupljanje podataka}

Za potrebe prikupljanja podataka kreiran je korisnički nalog na platformi MTurk u ulozi poslodavca, odnosno subjekta koji podnosi zahtev (Requester). Nakon kreiranja naloga, kreiran je zahtev za izradu zadatka takozvanog HIT-a (Human inteligence task) koji su zainteresovani korisnici mogli da izvrše. Ukupan vremenski period za prikupljanje podataka iznosio je 16 dana. Nagrada za uspešno popunjen upitnik za izvršioce bila je $0.05 \$$. Prosečno vreme popunjavanja upitnika iznosilo je 4 minuta.

\section{Uzorak}

Istraživanje je izvedeno na prigodnom uzorku od 746 ispitanika, 278 muškaraca i 468 žena prosečnog uzrasta 35.2 godina. Prema mestu stanovanja $76.6 \%$ uzorka čine stanovnici Severne Amerike, 12.9\% stanovnici Azije, 7.4\% Evrope, 1.6\% Afrike, 1.1\% Južne i Centralne Amerike i manje od 1\% iz Australije. U uzorku su zastupljene sve uzrasne i socijalno-demografske grupe punoletnih ispitanike.

Veličina uzorka je odabrana nakon analize statističke snage za jednosmerni t-test razlike između prosečnih vrednosti dva nezavisna uzorka, pomoću $\alpha=0.05$, snage $\mathrm{f}=0.80$, i za mali očekivani efekat $(\mathrm{d}=0.3)[18,19]$. Uz navedene pretpostavke, minimalna veličina uzorka treba da iznosi 139 ispitanika u svakoj grupi, odnosno 556 ispitanika ukupno. Zbog specifičnosti teme i načina prikupljanja podataka broj ispitanika ženskog pola značajno je premašio projektovanu kvotu za vreme koje je bilo potrebno da se dostigne projektovani minimum ispitanika muškog pola čime je obezbeđena dodatna snaga statističkog zaključivanja kako za subuzorak isputanika ženskog pola tako i za ukupan uzorak. 
Svi ispitanici su se sami prijavili za učešće $u$ istraživanju, bili su unapred pismeno upoznati sa zadacima, da će podaci biti korišćeni isključivo anonimno i da u svakom trenutku mogu da se povuku iz istraživanja bez ikakvih posledica. Istraživanje je izvedeno u skladu sa Etičkim principima i kodeksom propisanim od strane Američe Asocijacije Psihologa (APA).

\section{Postupak}

Svi ispitanici su preko mrežne platforme MTurk dobili da reše anonimnu anketu koja se sastojala iz dva dela. Prvi deo su činila pitanja koja se odnose na socijalno-demografski status ispitanika (pol, obrazovanje, mesto rođenja, mesto stanovanja, bračni status, broj dece, obrazovni nivo, radno mesto), proučavanje tema vezanih za bezbednost hrane tokom školovanja i samoprocene: zabrinutosti za pojavu stomačnih tegoba na putovanjima, nivoa informisanosti o bezbednosti hrane i učestalosti iskustva pojave stomačnih tegoba na putaovanju. Drugi deo činio je Upitnik stava bezbednosti hrane tokom putovanja (SBH-P), koji je konstruisan na opisan način i sastoji se od 32 tvrdnje na koje se odgovara putem petostepene skale procene likerovog tipa.

\section{Merenje}

Nakon prikupljanja, u cilju vršenja daljih analiza podaci su kodirani i tranformisani u numeričku maticu. Podaci iz prvog dela ankete transformisani su u nominalne i ordinalne skale prema odgovorima ispitanika i njihovoj učestalosti. Odgovori na 32 tvrdnje iz SBH-P pretvoreni su u ukupni prosečni skor koji se kreće od izrazito negativnog i nebezbednog stava (1) do izrazito pozitivnog i bezbednog stava (5).

\section{Obrada podataka}

$\mathrm{Na}$ osnovu izračunatih ukupnih skorova ispitanika na SBH-P u cilju provere metrijskih karakteristika urađena je deskriptivna statistička analiza kako celog uzorka tako i subuzorka muškaraca i žena.

Zatim je na odgovorima ispitanika na svako pojedinačno pitanje u okviru SBH-P urađena analiza pouzdanosti putem izračunavanja Kronbahovog alfa koeficijenta i metodom podele na pola (split-half). Opisana analiza pouzdanosti sprovedena je takođe na ukupnom uzorku i subuzorcima muškaraca i žena.
Diskriminativnost upitnika proverena je analizom varijanse, odnosno poređenjem prosečnih odgovora na SBH-P ispitanika koji su tokom školovanja izučavali teme povzane sa bezbednošću hrane i onih koji to nisu.

Eksterna validnost ukupnog skora na SBH-P testirana je korelacionom analizom odnosno proverom povezanosti postignuća na SBH-P i samoprocene: zabrinutosti za pojavu stomačnih tegoba na putovanjima, nivoa informisanosti o bezbednosti hrane i učestalosti iskustva pojave stomačnih tegoba na putovanju.

Za potrebe transformacije sirovih podataka u numeričke matrice korišćen je Majksrosoft Eksel (Microsoft Exel) 2007, statističke analize su vrešene pomoću SPSS 20. softverskog paketa dok je analiza snage urađena korišćenjem Dži Pauver (GPower) 3.1.

\section{REZULTATI I DISKUSIJA}

Deskriptivna statistička analiza (Tabela 1.) urađena je na nivou ukupnih skorova Upitnika stava o bezbednosti hrane tokom putovanja (SBH-P) za ceo uzorak ispitanika kao i za poduzorke muškaraca i žena. Greška ocene prosečne vrednosti u populaciji znose $0.62 \% \mathrm{za}$ ceo uzorak, $0.95 \%$ za muškarce i $0.62 \%$ za žene. Koeficijent varijacije iznosi 13.71 za ceo uzorak, $14.24 \%$ za muškarce i 13,58\% za žene. Veličine Skjunisa i Kurtozisa ukazuju da ne postoje značajana odstupanja od normalne distribucije.

Tabela 1. Deskriptivna statitička analiza Upitnika stava o bezbednosti hrane tokom putovanja

\begin{tabular}{|c|c|c|c|c|}
\hline \multicolumn{2}{|c|}{ Deskriptivna analiza $^{a}$} & $\begin{array}{c}\text { SBH- } \\
\text { P U }\end{array}$ & $\begin{array}{c}\text { SBH- } \\
\text { P M }\end{array}$ & $\begin{array}{c}\text { SBH- } \\
\text { P Ž }\end{array}$ \\
\hline & $N$ & 746 & 278 & 468 \\
\hline & Min. & 1.53 & 1.53 & 1.69 \\
\hline & Maks. & 4.38 & 4.38 & 4.38 \\
\hline \multirow{3}{*}{$\begin{array}{l}\text { Aritmetička } \\
\text { sredina }\end{array}$} & Statistik & 3.21 & 3.16 & 3.24 \\
\hline & Std. $g r$. & .02 & .03 & .02 \\
\hline & Std. dev. & .44 & .45 & .44 \\
\hline \multirow{2}{*}{ Skjunis } & Statistik & -.11 & -.11 & -.12 \\
\hline & Std. gr. & .09 & .15 & .11 \\
\hline \multirow{2}{*}{ Kurtozis } & Statistik & .02 & -.31 & -.15 \\
\hline & Std. $g r$. & .18 & .30 & .23 \\
\hline
\end{tabular}

${ }^{a}$ Legenda: skor na upitnku stava o bezbednosti hrane na putovanjima za ceo uzotrak (SBH-P U) i pod uzorke muškaraca (SBH-P M) i žena (SBHP Ž), standardna greška (Std. gr.), standardna devijacija (Std. dev.) 
Rezultati deskriptivne statističke analize (Tabela 1.) na nivou ukupnih skorova SBH-P za ceo uzorak ispitanika kao i za poduzorke muškaraca i žena ukazuju na dobre metrijske karakteristike mernog instrumenta.

Analize varijanse pokazala je da postoje statistički značajne razlike u ukupnom skoru na SBH-P između ispitanika koji su tokom obrazovanja izučavali teme iz oblasti bezbednosti hrane i onih koji to nisu za ukupan uzotak $[\mathrm{F}(1,745)=27.24 ; \mathrm{p}<.000]$, kao i za pod uzorke muškaraca $[\mathrm{F}(1,276)=15.01 ; \mathrm{p}<.000]$ i žena $[\mathrm{F}(1,467)=15.37 ; \mathrm{p}<.000]$.

Rezultati analize varijanse govore u prilog diskriminativnosti mernog instrumenta.

Analiza pouzdanosti (Tabela 2.) urađena je na nivou pojedninačnih odgovora ispitanika na sve 32 stavke iz SBH-P na ukupnom uzorku ispitanika, kao i na pod uzorcima žena i muškaraca merenjem Kronbah Alfa (Cronbach's Alpha) koeficijenta.

Tabela 2. Analiza pouzdanosti Upitnika stava o bezbednosti hrane tokom putovanja metodom Kromabahove alfe

\begin{tabular}{ccccc}
\hline Analiza & $\begin{array}{c}\text { Kronbah } \\
\text { Kouzda- } \\
\text { bah } \\
\text { nosti }\end{array}$ & $\begin{array}{c}\text { Alfa na } \\
\text { osnovu } \\
\text { stan- } \\
\text { dardi- } \\
\text { zovanih } \\
\text { stavki }\end{array}$ & $\begin{array}{c}\text { Broj } \\
\text { stavki }\end{array}$ & $\begin{array}{c}\text { Broj } \\
\text { slučajeva }\end{array}$ \\
\hline $\begin{array}{c}\text { Ceo } \\
\text { uzorak }\end{array}$ & .80 & .80 & 32 & 746 \\
\hline Muškarci & .81 & .80 & 32 & 278 \\
\hline Žene & .80 & .80 & 32 & 468 \\
\hline
\end{tabular}

Pouzdanost SBH-P proverena je i metodom podele na pola (split-half) takođe na nivou pojedninačnih odgovora ispitanika na sve 32 stavke iz SBH-P na ukupnom uzorku ispitanika, kao i na pod uzorcima žena $\mathrm{i}$ muškaraca.

Rezultati analize pouzdanosti (Tabele 2. i 3.) govore o visokom nivou pouzdanosti mernog instrumenta, pogotovu uzimajući u obzir divergentnost merenih aspekata stava o bezbednosti hrane što rezultuje smanjenjem niva korelacije među stavkama (item-item).

Korelaciona analiza (Tabela 4.) pokazuje da postoje značajne pozitivne povezanosti $(\mathrm{p}<0.00)$ između skorova na SBH-P i samoprocene: zabrinutosti za pojavu stomačnih tegoba na putovanju, učestalosti iskustva pojave stomačnih tegoba na putovanjima i informisanosti o bezbednosti hrane. Dok je veza sa učestalošću pojave stomačnih tegoba slaba povezanost sa zabrinutoišću za pojavu stomačnih tegoba na putovanju i informisanosti o bezbednosti hrane umerenog tipa.

Tabela 3. Analiza pouzdanosti Upitnika stava o bezbednosti hrane tokom putovanja metodom podele na pola

\begin{tabular}{|c|c|c|c|c|c|}
\hline \multicolumn{3}{|c|}{ Analiza pouzdanosti } & $\begin{array}{c}\text { Ceo } \\
\text { uzorak }\end{array}$ & $\begin{array}{l}\text { Muš- } \\
\text { karci }\end{array}$ & Žene \\
\hline \multirow{4}{*}{$\begin{array}{c}\text { Kron- } \\
\text { bah } \\
\text { Alfa }\end{array}$} & Deo & $\begin{array}{l}\text { Vred- } \\
\text { nost }\end{array}$ & .77 & .78 & .76 \\
\hline & 1 & $\begin{array}{l}\text { Broj } \\
\text { stavki }\end{array}$ & 16 & 16 & 16 \\
\hline & Deo & $\begin{array}{l}\text { Vred- } \\
\text { nost }\end{array}$ & .63 & .62 & .64 \\
\hline & 2 & $\begin{array}{c}\text { Broj } \\
\text { stavki }\end{array}$ & 16 & 16 & 16 \\
\hline \multicolumn{3}{|c|}{ Korelacija između delova } & .54 & .54 & .53 \\
\hline \multirow{2}{*}{$\begin{array}{c}\text { Spir- } \\
\text { man- } \\
\text { Braunov } \\
\text { koefi- } \\
\text { cijent }\end{array}$} & \multicolumn{2}{|c|}{ Jednaka dužina } & .70 & .70 & .69 \\
\hline & \multicolumn{2}{|c|}{$\begin{array}{c}\text { Ne jednaka } \\
\text { dužina }\end{array}$} & .70 & .70 & .69 \\
\hline \multicolumn{3}{|c|}{$\begin{array}{l}\text { Gutmanov koeficijent } \\
\text { podele na pola }\end{array}$} & .70 & .70 & .69 \\
\hline
\end{tabular}

Tabela 4. Korelaciona analiza: vrednosti $r$ koeficijenata i njihova statistička značajnost za varijable samoprocene: zabrinutosti za pojavu stomačnih tegoba na putovanjima, nivoa informisanosti o bezbednosti hrane i učestalosti iskustva pojave stomačnih tegoba na putaovanju i ukupnog postignuća ispitanika na Upitniku stava o bezbednosti hrane tokom putovanja

\begin{tabular}{|c|c|c|c|c|}
\hline \multicolumn{2}{|c|}{ Korelaciona analiza } & $\begin{array}{l}\text { Zabri- } \\
\text { nutost }\end{array}$ & $\begin{array}{c}\text { Inform- } \\
\text { isanost }\end{array}$ & $\begin{array}{c}\text { Stomačne } \\
\text { tegobe }\end{array}$ \\
\hline \multirow{3}{*}{$\begin{array}{l}\text { SBHP } \\
\text { U }\end{array}$} & $\begin{array}{l}\text { Pirsonova } \\
\text { korelacija }\end{array}$ &, $478^{\star *}$ &, $320^{\star *}$ &, $294^{* *}$ \\
\hline & Značajnost &, 000 &, 000 & 000 \\
\hline & $\mathbf{N}$ & 746 & 746 & 746 \\
\hline
\end{tabular}

Rezultati korelacione analize (Tabela 4.) govore $\mathrm{u}$ prilog eksterne validnosti mernog instrumenta.

Demonstrirana brzina i lakoća prikupljana obimnog globalnog uzorka potvrda je ranijih teorijskih predviđanja potencijala upotrebe mrežnih paltformi naučnim istraživanjima [9]. 


\section{ZAKLJUČAK}

Na osnovu iznetih analiza može se izvesti zaključak da je Upitnik stava o bezbednosti hrane tokom putovanja validan merni instrument pogodan za dalja istraživanja ove teme. Takođe, primena informacione tehnologije, odnosno mrežnih platformi u prikupljanju podataka obezbeđuje brzo i efikasno sprovođenja istraživanja, zbog čega se i ono preporučuje za dalju upotrebu kako $\mathrm{u}$ istraživanju ove teme tako i šireg domena naučnih problema. Izbor mrežne platforme MTurk pokazala se kao dobar jer je obezebedio ekonomično, brzo i jednostavno prikupljanje velikog broja upotrebljivih podataka. Prikupljeni podaci, obrađeni primenom adekvatnih statističkih metoda i analizirani mogu mogu doprineti boljoj edukaciji putnika po pitanju bezbednosti hrane na putovanjima, što značajno može smanjiti broj oboljenja izazvanih nebezbednom hranom na samom putovanju.

\section{LITERATURA}

[1] World Health Organisation (2015). WHO estimates of the global burden of foodborne diseases: foodborne disease burden epidemiology reference group 2007-2015. Geneva

[2] Hussain M., A. and Dawson C O (2013). Economic Impact of Food Safety Outbreaks on Food Businesses. Foods, 2, pp. 585-589

[3] Giddings, SL, Stevens AM, Leung DT (2016). Traveler's Diarrhea Med Clin N Am 100, pp. 317-330

[4] Sanford C A Pottinger, PS., Jong EC. (2017). The Travel and Tropical Medicine Manual Fifth Edition. Oxford: Elsevier Inc.

[5] Gupta, R. K., Dudeja, \& Minhas, S. (Urednici). (2016). Food Safety in the 21st Century Public Health Perspective. Elsevier Inc.

[6] Kilibarda, N. (2019). Bezbednost hrane. Beograd: Univerzitet Singidunum.

[7] Rot, N. (2010). Osnovi socijalne psihologije. Beograd: Zavod za udžbenike i nastavna sredstva.
[8] Riddle MS, Connor BA, Beeching NJ, DuPont HL, Hamer DH, Kozarsky P, Libman M, Steffen R, Taylor D, Tribble DR, Vila J, Zanger P. (2017). Guidelines for the prevention and treatment of travelers' diarrhea: a graded expert panel report. Journal of Travel Medicine, 24 (suppl_1):S57-S74

[9] Milošević, M. Ristić, I. (2016). „Nov metodološki pristup studijama kreativnosti“. In Medias Res časopis filozofije medija, 5(8). Pp. 1237-1250.

[10] Howe, J. (2006, June 1). The Rise of Crowdsourcing. Wired. Retrieved from https://www.wired. com/2006/06/crowds/

[11] Amazon Mechanical Turk. (2019, November 3). Retrieved March 11, 2019, from https://www.MTurk. $\mathrm{com} /$

[12] Casler, K., Bickel, L., \& Hackett, E. (2013). Separate but equal? A comparison of participants and data gathered via Amazon's MTurk, social media, and face-to-face behavioral testing. Computers in $\mathrm{Hu}$ man Behavior, 29(6), pp. 2156-2160. https://doi. org/10.1016/j.chb.2013.05.009

[13] Huff, C., \& Tingley, D. (2015). "Who are these people?" Evaluating the demographic characteristics and political preferences of MTurk survey respondents. Research \& Politics, 2(3), 205316801560464. https://doi.org/10.1177/2053168015604648

[14] Paolacci, G. (2010). Running experiments on Amazon Mechanical Turk. Judgment and Decision Making, 5(5), 9.

[15] Liu, S. Q., \& Mattila, A. S. (2017). Airbnb: Online targeted advertising, sense of power, and consumer decisions. International Journal of Hospitality Management, 60, pp. 33-41. https://doi.org/10.1016/j. ijhm.2016.09.012

[16] Mason, W., \& Suri, S. (2012). Conducting behavioral research on Amazon's Mechanical Turk. Behavior Research Methods, 44(1), pp. 1-23. https://doi. org/10.3758/s13428-011-0124-6

[17] Statista. (2019, November 3). IoT: number of connected devices worldwide 2012-2025. Retrieved March 11, 2019, from https://www.statista.com/ statistics/471264/iot-number-of-connected-devices-worldwide/

[18] Cohen, J. (1959) Statistical Power Analysis for the Behavioral Sciences. New York: Academic press.

[19] Faul, F. (2014) G Power 3.1.9.2. [Software]. Kiel: Universitat Kiel. 